\title{
Development of Flow Sensors Realized with Printed Circuit Board Technology for Air Conditioning Systems
}

\author{
Thomas Glatzl ${ }^{1}$, Samir Cerimovic ${ }^{1}$, Harald Steiner ${ }^{1}$, Almir Talic ${ }^{1}$, Roman Beigelbeck ${ }^{1}$, Artur \\ Jachimowicz', Thilo Sauter', Franz Keplinger ${ }^{2}$ \\ ${ }^{1}$ Center for Integrated Sensor Systems, Danube University Krems, Wiener Neustadt, Austria, \\ thomas.glatzl@donau-uni.ac.at \\ ${ }^{2}$ Institute of Sensor and Actuator Systems, Vienna University of Technology, Vienna, Austria
}

\begin{abstract}
This paper addresses the development of a flow sensor optimized for heating ventilating and air conditioning systems. The sensor is based on the printed circuit board technology facilitating robust, flexible (in design layout), and cost-effective devices. Two approaches for measuring fluid quantities like flow velocity and flow rate are investigated in this context. The first one relying on hot-film transduction shows severe limitations while the second one based on calorimetric transduction is able to overcome these drawbacks. Guided by extensive computer numerical simulations, two sensor embodiments were investigated, optimized, and fabricated. Afterwards, the sample devices are characterized by measurements and compared to simulation results which both turned out to be in good agreement.
\end{abstract}

Key words: flow sensor, hot-film, calorimetric, printed circuit board, air conditioning systems

\section{Introduction and Motivation}

The supply of today's urban agglomerations would not be possible without modern energy technology. Big residential and commercial buildings demand continuous power supply where about $35 \%$ of their total energy use is consumed by air conditioning and heating units, the so-called HVAC (heating ventilating and air conditioning) systems. Two thirds of this amount is imputable to private living space and one third to service buildings [1]. In the private sector, significant improvements have been made to reduce the overall energy consumption, but still actions have to be taken in the service section. Analyses have shown that up to $40 \%$ of the energy demand can be saved by optimizing the air ventilation and conditioning systems [2]. In order to achieve this, the installation of a sufficient amount of sensors and actuators is required to obtain a detailed insight into the thermal management of the building and in further consequence to enhance the HVAC system. Flow parameters like flow velocity, flow rate, and flow direction are potential key parameters in the optimization of building automation and environmental monitoring.
If the focus is on robust, flexible (regarding design layout), and cost-effective sensors rather than high sensing accuracies, then manufacturing technologies capable of mass production have to be taken into account. Moreover, these technologies should only consist of a few and inexpensive process steps to keep the total costs of the system at a reasonable level. Printed circuit board (PCB) is such a technology which is commonly used in consumer electronics as well as in many medical, aerospace, industrial applications. Therefore, it is not surprising that this technology has become interesting for the production of various types of sensors [3-5].

\section{Hot-Film Approach - Sensor Design}

The first approach is based on hot-film anemometry $[6,7]$ where the convective cooling of a passing fluid changes the temperature of a heating film and, consequentially, its electrical resistance. This resistance change can then be exploited to acquire information about the fluid velocity. Hot-wire and hot-film anemometers can be operated in two different modes [8]. In the first mode, the heater is supplied either with a constant current (CCA - constant current anemometer) or a constant voltage (CVA constant voltage anemometer). The flow dependent resistance change of the heater is 
detected by measuring the heater voltage or the probe current, respectively. In the second operating mode, a constant temperature difference between the probe and the ambient is established by means of an electronic controller (CTA - constant temperature anemometer). The voltage or current required to maintain the constant excess temperature can be used as output quantity for the flow velocity.

Figure 1 shows a PCB-based hot-film sensor where the sensor embodiment is characterized by a meandering pattern with four strips. The distance between adjacent strips and the strip width amounts to $100 \mu \mathrm{m}$ while the overall PCB length is given by $5 \mathrm{~cm}$. The fabrication of the device started from a flexible standard FR4 epoxy glass substrate $(100 \mu \mathrm{m}$ thickness $)$ laminated with a copper layer of a thickness of $18 \mu \mathrm{m}$ which was then narrowed down to $5 \mu \mathrm{m}$ by means of wet etching. Finally, the PCB was protected with a solder resist with a thickness of $40 \mu \mathrm{m}$. In sensor operation, this copper layer serves simultaneously as heating and temperature sensing element.

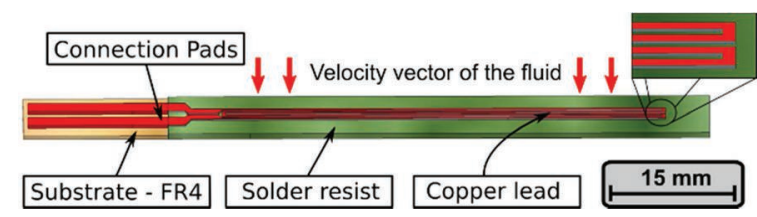

Figure 1: Hot-Film anemometer produced on a PCB where the substrate (beige) has a thickness of $100 \mu \mathrm{m}$. The copper leads (red) are grinded from $18 \mu \mathrm{m}$ to $5 \mu \mathrm{m}$ and the solder resist (green) cover the copper leads except the connection pads.

Before the actual measurements in the flow pipe, the copper layer has to be characterized regarding its thermal thin-film properties. For that reason, the PCB device was placed in a temperature chamber and the resistance of the thin film was measured continuously at different temperature values (Figure 2). The temperature-resistance equation for the copper layer reads:

$R=R_{20} *(1+\alpha * \Delta T)$,

where $\Delta T=T-20^{\circ} \mathrm{C}$ and $T$ are excess temperature and the current layer temperature, respectively. $R_{20}$ denotes the resistance in Ohm at $20^{\circ} \mathrm{C}$ and $\alpha$ is the temperature coefficient of resistance (TCR). From these measurements, the two important parameters $R_{20}=7.02 \Omega$ and $\alpha=3.66 \mathrm{e}^{-2} 1 / \mathrm{K}$ can be calculated from equation (1). This TCR is in accordance with the values that can be found in the literature [9].

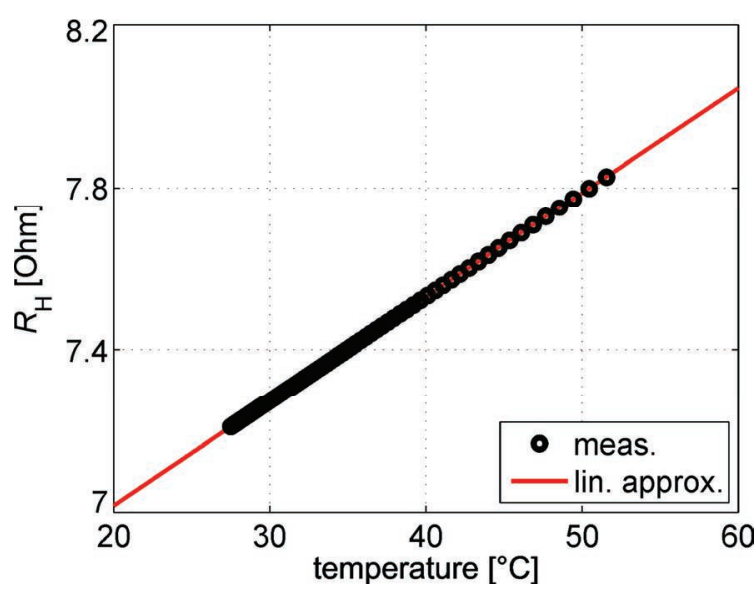

Figure 2: The measured heater resistance $\left(R_{H}\right)$ of the copper lead (heater, black rings) over temperature. The linear approximation (red) is calculated from the measurement points.

\section{Experimental Set-Up}

The experimental set-up is illustrated in Figure 3. A PMMA-pipe with a total length of $82 \mathrm{~cm}$ and a diameter of $d=5 \mathrm{~cm}$ was used as a flow channel. A fan (AVC double vane van, $12 \mathrm{~V}, 1.14 \mathrm{~A}$ ) was mounted at the one end of the pipe in order to establish a constant and well defined air flow. A PC controlled power supply regulates the voltage of the fan and thereby sets the flow velocity in the channel. Average flow velocities in the range of 0.5 $3.5 \mathrm{~m} / \mathrm{s}$ are achievable with the chosen fan type. The sensor was placed in the middle of the pipe and powered with a constant heating current of $I_{\mathrm{H}}=115 \mathrm{~mA}$ which corresponds to a heating power of $100 \mathrm{~mW}$. The cooling air flow decreases the heater resistance. Since the heating current is imposed, the voltage across the heater follows this trend.

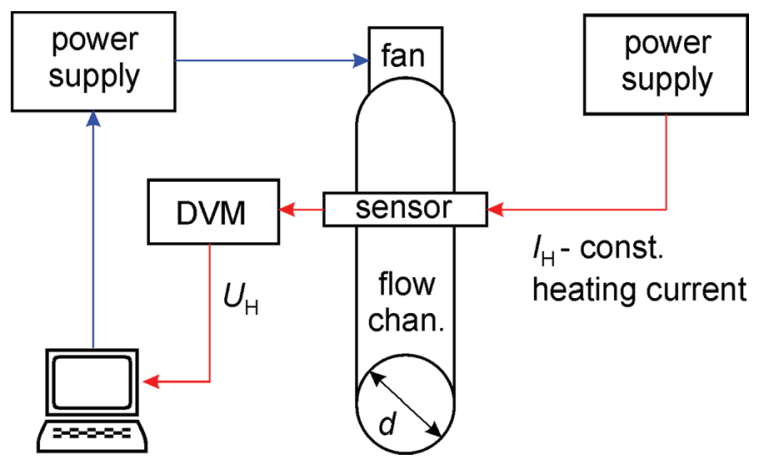

Figure 3: Picture of the experimental set-up. The sensor was placed in the middle of the flow channel and supplied with a constant current. An air flow was induced with a fan and the voltage on the heater has been measured with a digital voltage multimeter (DVM). 


\section{Measurement Results}

In Figure 4 the voltage across the heater $\left(U_{\mathrm{H}}\right.$, red curve) is plotted over the average flow velocity in the pipe. $U_{H}$ was measured by a digital voltmeter (DVM) connected to a PC. A hundred measurement points were recorded from each individual flow velocity and the resulting mean value was used for the sensor output characteristic.

Three major drawbacks of the hot-film sensor can be found by analyzing the output characteristic. The first one is the saturation of the output signal. The aim of the described design was to measure velocities up to $10 \mathrm{~m} / \mathrm{s}$. However, according to Figure 4 the sensitivity (slope of the output characteristic) above $3 \mathrm{~m} / \mathrm{s}$ is barely sufficient these flow velocities. The second one is the direction independence, i.e. the output characteristic is an even function and, therefore, not dependent on the direction of the fluid flow. The third one is the ambient temperature dependence of the output characteristic. Consequently, the ambient temperature has to be measured too in order to compensate this effect.

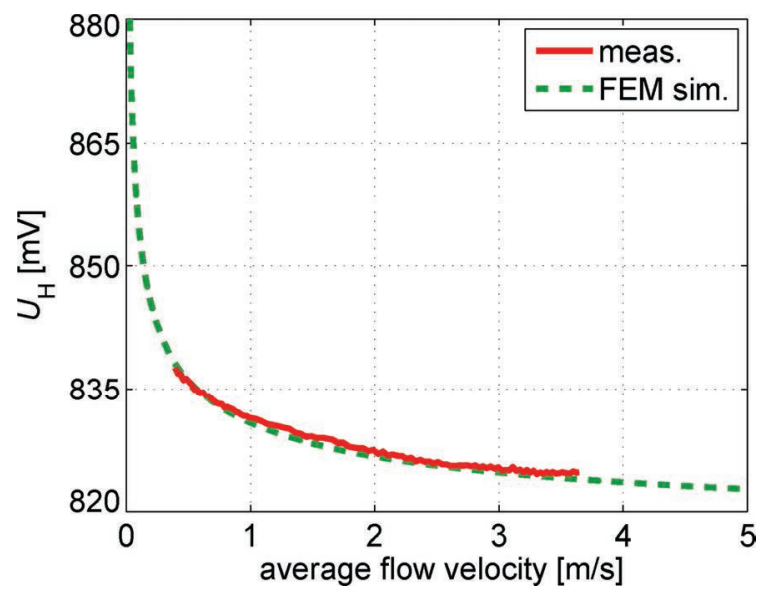

Figure 4: Voltage of the heater $\left(U_{\mathrm{H}}\right)$ over the average flow velocity in the channel. The measured results are compared with FEM simulation results.

\section{Calorimetric Approach - New Sensor Design}

Due to mentioned drawbacks, the hot-film approach is not useable for HVAC systems. Therefore, a PCB with a new sensor design is proposed, which is based on the calorimetric transduction principle. The calorimetric method consists of a heating element and spatially separated temperature sensing elements. The latter are often symmetrically placed up- and downstream of the heater. This allows for detection of the flow direction.
Figure 5 shows a sketch of the new sensor embodiment. The heater design (red) was adopted from the hot-film transducer. To determine the temperature at the up- and downstream site of the heater, four additional copper leads (blue and purple) were laminated on the substrate. Contrary to the heater, they consist only of two strips. The overall PCB width now amounts $2.5 \mathrm{~mm}$ and the length remains the same $(5 \mathrm{~cm})$.

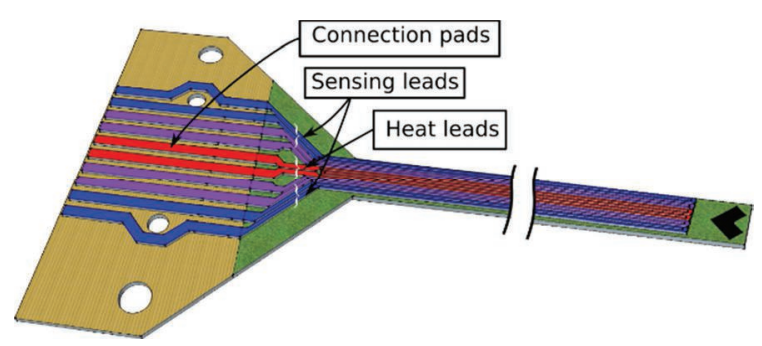

Figure 5: Schematic of the calorimetric transducer layout: The length of the meander is $50 \mathrm{~mm}$ and the overall thickness is about $140 \mu \mathrm{m}(100 \mu \mathrm{m}$ substrate and $40 \mu \mathrm{m}$ solder resist). Copper layers, $5 \mu \mathrm{m}$ thick are embedded in the solder resist. The heating leads are red, the sensing ones are blue and purple, the solder resist is green and the substrate is yellow. At the left of the transducer are connection pads for soldering.

\section{FEM Simulation}

A 2D-FEM (Finite Element Method) model of the sensor was developed, in order to predict the behavior of the transducer and to optimize the layout. Since all sensor components (the thermistors and the heater) exhibit a large extension perpendicular to the flow direction, two-dimensional modeling is reasonable.

Comsol Multiphysics was applied for the simulation. The model is based on the crosssectional view depicted in Fig. 6a. The sensor is placed in the centre of the flow channel (corresponding to the experimental PMMA-pipe arrangement). The conjugated heat transfer module of Comsol Multiphysics combines heat transfer and fluid dynamics. A parabolic flow velocity profile was imposed inside the channel (Fig. 6b) and the non-slip boundary condition was applied to all surfaces (i.e, channel walls and sensor surface).

The software package solves the incompressible Navier-Stokes equation in order to get the velocity field inside the channel and around the sensor (indicated with red arrows). Subsequently, the heat transfer equation incorporating conductive and convective heat transfer is solved. The boundary conditions for this mode at the in- and outlet of the flow 


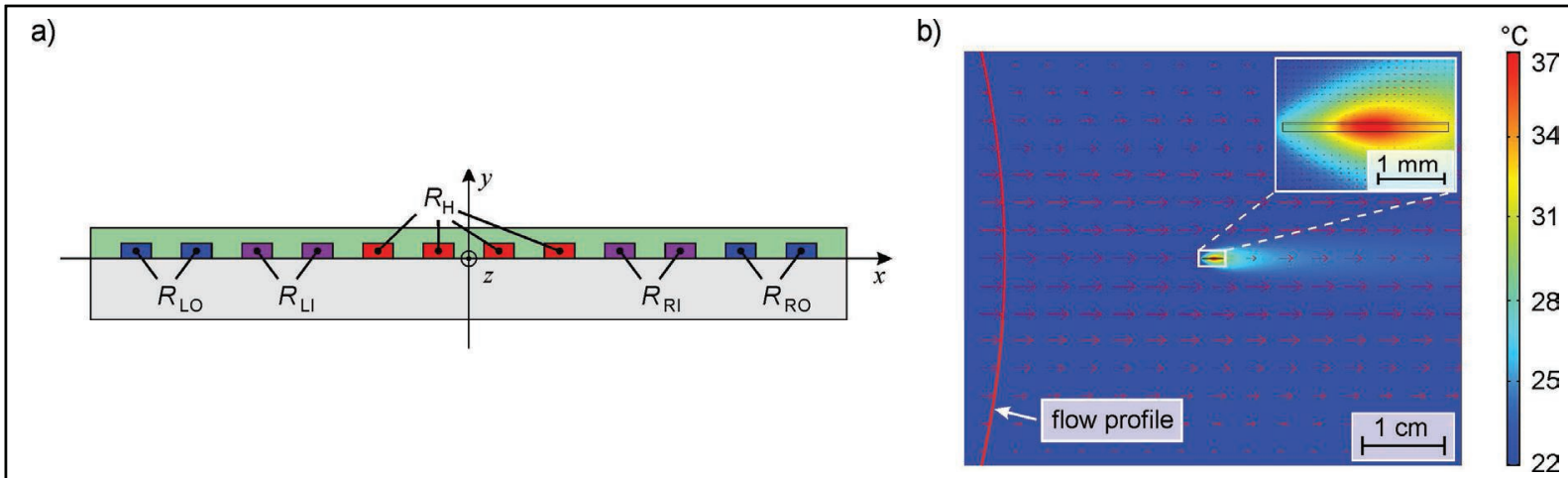

Figure 6: a) FEM model cross section of the calorimetric flow sensor. Grey is the FR4 substrate, green the solder resist, red the heater leads $\left(R_{\mathrm{H}}\right)$, blue and purple the sensing leads. The indexes indicate position on the PCB: L/R means left/right to the hater, O/I means outer/inner thermistor. b) Result of the FEM simulation. Red arrows indicates the velocity field at the average flow velocity of $v=0.1 \mathrm{~m} / \mathrm{s}$.

channel are implemented as convective flux while the remaining parts of the model circumference were kept at ambient temperature $\left(T_{\mathrm{amb}}=22^{\circ} \mathrm{C}\right)$. This is also the initial temperature value for all domains.

\section{Simulation Results}

First, only the hot-film sensor was simulated, i.e., the thermistors left and right from the heater were omitted. A constant heating power was imposed at the heater corresponding to the heating with a constant current of $I_{\mathrm{H}}=115 \mathrm{~mA}$ like in the measurements. The simulation and measurements results are compared in Figure 4. A very good agreement between simulation and measurement proofs the feasibility of the FEM-approach.

Next, the thermistors were taken into account in the simulations. They are supplied with a heat energy that is equivalent to a current of $I_{0}=10 \mathrm{~mA}$. Figure $6 \mathrm{~b}$ shows the simulated spatial temperature distribution $T$ at an average flow velocity of $v=0.1 \mathrm{~m} / \mathrm{s}$. The excess temperatures $\Delta T$ at the thermistor sites were calculated by integrating the temperature $T$ over the thermistor area. Applying equation (1), the electrical resistances, and, hence, the voltages across each thermistor can be calculated $\left(U_{R O}\right.$, $U_{R l}, U_{L l}, U_{L O}$ ).

Finally, there were three relevant voltages deduced:

1. Sum of the left side thermistor voltages minus the sum of the right side

$$
\begin{aligned}
& U_{1}=\left(U_{R O}+U_{R I}\right)-\left(U_{L I}+U_{L O}\right) \\
& \propto\left(T_{R O}+T_{R I}\right)-\left(T_{L I}+T_{L O}\right) \\
& \propto \Delta T_{R}-\Delta T_{L},
\end{aligned}
$$

where $T_{R \text {,mean }}$ and $T_{L \text {,mean }}$ denote the mean temperature of the right and left part of the sensor regarding the heater, respectively. The sign of this output can be used to detect the flow direction.

2. Sum of the outer thermistor voltages minus the sum of the inner thermistor voltages

$$
\begin{aligned}
& U_{2}=\left(U_{L I}+U_{R I}\right)-\left(U_{L O}+U_{R O}\right) \\
& \propto\left(T_{L I}+T_{R I}\right)-\left(T_{L O}+T_{R O}\right) \\
& \propto \Delta T_{I}-\Delta T_{O},
\end{aligned}
$$

where $T_{1, \text { mean }}$ and $T_{O \text {,mean }}$ denote the mean temperature of the inner and outer part of the sensor, respectively. This signal describes the difference between the temperature in the middle of PCB (inner thermistors) and the temperature at the periphery of the PCB (outer thermistors).

\section{Sum of all thermistor voltages}

$$
\begin{aligned}
& U_{3}=U_{L O}+U_{L I}+U_{R I}+U_{R O} \\
& \propto T_{L O}+T_{L I}+T_{R I}+T_{R O} \\
& \propto \Delta T_{s}
\end{aligned}
$$

where $T_{S}$ denotes the mean temperature of the whole PCB. This signal describes the cooling of the PCB and features the same trend as the $U_{H}$ characteristic in Figure 4.

The main disadvantage of the CCA-mode is the saturation of the output characteristic at higher flow velocities (Fig. 4). For constant heating power of $100 \mathrm{~mW}$ and $v>3 \mathrm{~m} / \mathrm{s}$ the convective cooling is so efficient, that the difference between the hot-film temperature and the fluid temperature tends to zero, resulting in the saturation of the output signal. 
The heating power at higher flow velocity must be increased to overcome the saturation. This operating mode is achieved by electronically controlling the heater voltage and thus the heating power to keep the temperature difference between the sensor and the fluid at a constant level (CT - constant temperature mode of the calorimetric flow sensor) [10].

The sensor temperature can be obtained from the voltage $U_{3}$, whereas the ambient fluid temperature must be measured by an external temperature sensor. Hence, a compact flow sensor based solely on PCB technology cannot be used in such a measurement configuration.

Therefore, we propose to control the voltage $U_{2}$ (3). Keeping this voltage constant by an electronic controller results in a constant difference between the mean temperatures of the inner and outer part of the sensor $\Delta T_{1}$. $\Delta T_{\mathrm{O}}=$ const. The temperature at the upstream edge of the sensor (measured by $R_{L O}$, assuming a flow from the left side in Fig. 6a) is near the fluid temperature, whereas the temperature at the opposite downstream edge is much higher due to the convective heat transport from the heater. Thus, the mean temperature at the sensor edge $\left(T_{0}\right)$ differs from the fluid temperature. Nevertheless, the increase of the heater voltage in this quasi CTmode should be sufficient enough for precise measurements in higher velocity ranges. This behavior was proven by FEM simulations.

A temperature difference of $T_{1}-T_{0}=4 \mathrm{~K}$ was chosen in the simulation and the input energy at the heater was adjusted until this difference was reached. Moreover, assuming a $10 \mathrm{~mA}$ supply current for all temperature leads, the voltage across the thermistors is evaluated in order to calculate $U_{1}$ and $U_{2}$.

The results gained from this simulation are depicted in Figure 7. The required heater voltage $U_{H}$ to keep the voltage $U_{2}$ (corresponding to $\Delta T_{1}-\Delta T_{\mathrm{O}}=4 \mathrm{~K}$ ) at a constant level as well as the corresponding voltage $U_{1}$ are plotted over the average flow velocity. A signal saturation occurs for $U_{A}$ above $15 \mathrm{~m} / \mathrm{s}$ in the described measurement media, which is adequate for the use in HVAC systems. Moreover, as the controller keeps the temperature difference (rather than the absolute value of the temperature) constant, variations of the fluid temperature have no influence on the output signal. $U_{1}$ has a high initial sensitivity (slope of the characteristic), reaches its maximal value around $7 \mathrm{~m} / \mathrm{s}$ and decrease for higher flow velocities. Therefore, it can only be used for low flow range of $v<0.5 \mathrm{~m} / \mathrm{s}$. But, the voltage $U_{1}$ can be used to detect the direction of the flow, since its sign changes when the flow changes direction.

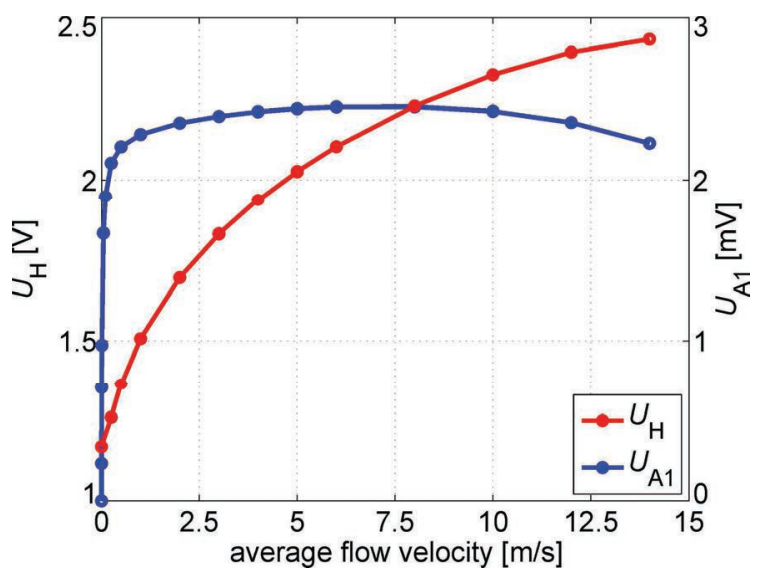

Figure 7: Simulation result of the heater voltage $U_{H}$ as well as the voltage $U_{1}$ over the average flow velocity when the voltage $U_{2}$ is kept constant (corresponding to $\Delta T_{I}-\Delta T_{O}=4 \mathrm{~K}$ ).

\section{Conclusion}

A development of flow sensors for heating, ventilating, and air conditioning is presented in this paper. The aim was to use standard, lowcost and high-efficient technologies such as printed circuit board. The first approach was based on the hot-film transduction principle. A thin copper film was laminated on a FR-4 substrate. The characterization of the transducer revealed three major drawbacks: the saturation of the output characteristic, its temperature dependence, and no possibility to detect the direction of the flow.

Therefore, the sensor design was revised by adding four temperature sensors arranged symmetrically around the heater. An electronic controller adjusts the heater voltage, keeping the mean temperature difference between the central and periphery area of the PCB constant. In this operating mode, the output characteristic is strictly monotonic over the whole desired flow rang and does not depend on fluid temperature. Moreover, the flow direction can also be detected.

This work showed that flow sensors based on printed circuit board technology are feasible for HVAC systems. Future work will focus on two main topics. The first one addresses the development of the controller circuit and its optimization. Here, an analog controller can be replaced by alternative circuits such as the Sigma-Delta-Modulator [11]. Its quasi digital output facilitates the connection to a network node as a second goal. The second one deals with the fusion of the transducer, the 
electronics, and the network node to one complete system adapted for HVAC applications.

\section{Acknowledgements}

This work has been financially supported by the Austrian Research Promotion Agency (FFG, research grant 834175). The Center for Integrated Sensor Systems gratefully acknowledges partial financial support by the European Regional Development Fund (EFRE) and the province of Lower Austria.

\section{References}

[1] L. Pérez-Lombard, J. Ortiz, and C. Pout, "A review on buildings energy consumption information," Energy and Buildings, vol. 40, no. 3, pp. 394-398, Jan. 2008.

[2] K. Fitzner, Raumklimatechnik, 16. ed., vol. 2, 3 vols. Springer, 2008.

[3] A. Prijic, L. Vracar, D. Vuckovic, D. Milic, and Z. Prijic, "Thermal Energy Harvesting Wireless Sensor Node in Aluminum Core PCB Technology," IEEE Sensors Journal, vol. 15, no. 1, pp. 337-345, Jan. 2015.

[4] R. Nojdelov and S. Nihtianov, "CapacitiveSensor Interface With High Accuracy and Stability," IEEE Transactions on Instrumentation and Measurement, vol. 58, no. 5, pp. 1633-1639, May 2009.

[5] S. Cruz, J. C. Viana, D. Dias, and L. A. Rocha, "Pressure sensing platform for health monitoring," in 2014 IEEE International Symposium on Medical Measurements and Applications (MeMeA), 2014, pp. 1-5.

[6] S. Saremi, A. Alyari, D. Feili, and H. Seidel, "A MEMS-based hot-film thermal anemometer with wide dynamic measurement range," in 2014 IEEE SENSORS, 2014, pp. 420-423.

[7] J. T. W. Kuo, L. Yu, and E. Meng, "Micromachined Thermal Flow Sensors-A Review," Micromachines, vol. 3, no. 3, pp. 550-573, Jul. 2012.

[8] S. Cerimovic, A. Talic, R. Beigelbeck, H. Antlinger, T. Sauter, J. Nicolics, B. Jakoby, and F. Keplinger, "Bidirectional micromachined flow sensor featuring a hot film made of amorphous germanium," Measurement Science and Technology, vol. 24, no. 8, p. 084002, Aug. 2013.

[9] W. F. Leonard and H.-Y. Yu, "Thermoelectric power of thin copper films," Journal of Applied Physics, vol. 44, no. 12, pp. 53205323, Dec. 1973.
[10] F. Kohl, R. Fasching, F. Keplinger, R. Chabicovsky, A. Jachimowicz, and G. Urban, "Development of miniaturized semiconductor flow sensors," Measurement, vol. 33, no. 2, pp. 109-119, 2003.

[11] S. Cerimovic, A. Talic, R. Beigelbeck, T. Sauter, F. Kohl, J. Schalko, and F. Keplinger, "A Novel calorimetric flow sensor implementation based on thermal sigmadelta modulation," in 2009 IEEE Sensors, 2009, pp. 1923-1926. 